\title{
Endogenous Substance P Mediates Cold Water Stress-Induced Increase in Interleukin-6 Secretion from Peritoneal Macrophages
}

\author{
Goafa F. Zhu, ${ }^{1}$ Cheryl Chancellor-Freeland, ${ }^{1}$ Ari S. Berman, ${ }^{1}$ Reinhard Kage, ${ }^{2}$ Susan E. Leeman, ${ }^{2}$ \\ David I. Beller, ${ }^{3}$ and Paul H. Black ${ }^{1}$
}

Departments of ${ }^{1}$ Microbiology, ${ }^{2}$ Pharmacology, and ${ }^{3}$ Medicine, Boston University School of Medicine, Boston, Massachusetts 02118

Previous studies from this laboratory had shown that exposure of mice to cold water stress leads to an increase in the secretion of interleukin-1 (IL-1) and tumor necrosis factor- $\alpha$ (TNF $\alpha$ ) from their peritoneal macrophages. We now report that the secretion of IL-6 from peritoneal macrophages is also increased after cold water stress and that the peptide substance $\mathrm{P}(\mathrm{SP})$ participates in this stress-induced response. The stress paradigm involved subjecting male C57BL/6J mice to $5 \mathrm{~min}$ swim tests in $10 \pm 2^{\circ} \mathrm{C}$ water twice daily for $4 \mathrm{~d}$. Cold water stress augments the lipopolysaccharide-induced IL- 6 secretion from peritoneal macrophages, elevates immunoreactive SP (iSP) in the peritoneal wash fluid, and reduces iSP in certain peritoneum-containing tissues or organs (i.e., diaphragm, abdominal wall, ileum, and rectum). The $10 \mathrm{~d}$ stress time course studies indicate that increased IL-6 secretion is positively related to elevated iSP in the peritoneal wash fluid and inversely related to reduced iSP in certain peritoneum-containing tissues. Pretreatment with capsaicin, which depletes SP in the sensory nerve endings, eliminates stress-control differences in the peritoneal wash fluid and in certain peritoneal tissues. Moreover, RP67,580, a specific SP antagonist, eliminates the cold water stress-induced augmentation of IL-6 secretion from peritoneal macrophages. These results suggest that cold water stress promotes the release of SP from peritoneal tissues into the peritoneal cavity, where it participates in the cold water stress-induced macrophage functional alterations.

Key words: substance P; stress; macrophage; cytokine; interleukin-6; capsaicin; RP67,580
There have been many reports indicating that stress can affect immune functions (Irwin, 1993; Black, 1994a,b, 1995; Ursin, 1994). Most of these studies have focused on alterations of lymphocyte activity (Ottaway and Husband, 1994), whereas relatively few have investigated changes in macrophage activity (Coe et al., 1988; Brown and Zwilling, 1994; Fleshner et al., 1995) (for review, see Adams, 1994). Experiments in this laboratory have shown that cold water stress in mice can augment macrophage proinflammatory cytokine production. After cold water stress, interleukin-1 (IL-1) is secreted spontaneously (Jiang et al., 1990), whereas increased amounts of tumor necrosis factor- $\alpha$ (TNF $\alpha$ ) are secreted after exposure to lipopolysaccharide (LPS) (C. ChancellorFreeland, G. F. Zhu, A. S. Berman, D. I. Beller, S. E. Leeman, P. H. Black, unpublished observations). We now report the increase in IL-6 (another proinflammatory cytokine) secretion from elicited mouse peritoneal macrophages after cold water stress.

We have also investigated the participation of substance P (SP) in the cold water stress-induced alteration of cytokine secretion. $\mathrm{SP}$, an 11-amino-acid neuropeptide, is widely distributed in the CNS and PNS. It mediates pain, inflammation, and many other physiological and pathological processes (Pernow, 1983; Otsuka and Yoshioka, 1993). In the PNS, it is mainly present in peripheral sensory neurons, particularly in small unmyelinated fibers. It has

\footnotetext{
Received Nov. 21, 1995; revised Feb. 5, 1996; accepted March 6, 1996.

This research was supported by Grant F91-33 from the Whitehall Foundation, Palm Beach, FL; by the Jefferson L. Ford III Memorial Foundation, Bal Harbour, FL; and by the Cotsen Family Foundation in memory of Mrs. Sophie Cotsen.

Correspondence should be addressed to Dr. Paul H. Black, Department of Microbiology, Boston University School of Medicine, 80 East Concord Street, Boston, MA 02118 .

Copyright $\mathbb{C} 1996$ Society for Neuroscience $\quad 0270-6474 / 96 / 163745-08 \$ 05.00 / 0$
}

been identified in nerve endings throughout the body, including the skin, joints, and vascular, gastrointestinal, and mucosal tissues.

Evidence suggests that SP can affect immune functions and the inflammatory response at these sites (McGillis et al., 1990). SP induces the release of IL- 1 and TNF $\alpha$ from glial cells (Martin et al., 1993; Luber-Narod et al., 1994) and mononuclear leukocytes (Kimball et al., 1988); IL-1, IL-6, and TNF $\alpha$ from monocytes (Lotz et al., 1988; Laurenzi et al., 1990); affects cytokine secretion by bone marrow cells (Rameshwar et al., 1993, 1994, 1995); and primes neutrophils (Perianin et al., 1989; Lloyds et al., 1993, 1995) and eosinophils (Kroegel et al., 1990). Specific high-affinity SP receptors are present on lymphocytes (Payan et al., 1984; Stanisz et al., 1987; Bost, 1988), glial cells (Mantyh et al., 1989; Martin et al., 1993), mast cells (Piotrowski et al., 1987), and macrophages and monocytes (Hartung et al., 1986, 1988; Lotz et al., 1988; Bost et al., 1992). Taken together, the literature indicates that SP can function as an immune mediator involved in the modulation of inflammatory, hypersensitivity, cell-mediated, and humoral immune responses.

To determine whether SP participates in the stress-induced increase in IL-6 secretion from peritoneal macrophages, we measured SP concentrations in the peritoneal fluid that bathes the peritoneal macrophages. We also investigated the source of SP in the peritoneal fluid, as well as the effect of the SP antagonist RP67,580 on cytokine production.

\section{MATERIALS AND METHODS}

\section{Animals}

Male C57BL/6J mice were obtained at age 6-8 weeks from Jackson Laboratory (Bar Harbor, ME). Animals were housed, four or five per cage, under pathogen-free conditions on a $12 \mathrm{hr}$ light/ $12 \mathrm{hr}$ dark cycle 
(lights off at 6 P.M.) and allowed a minimum of $10 \mathrm{~d}$ acclimatization before experiments were conducted.

\section{Stress procedure}

The stress was administered twice daily ( 9 A.M. and 4 P.M.) for a duration of $5 \mathrm{~min}$ for $4 \mathrm{~d}$, except in the $10 \mathrm{~d}$ stress time course experiments, in which the stress was administered twice daily for the indicated number of days. We used a $4 \mathrm{~d}$ cold water stress paradigm because it was found to be optimal for detcetion of certain stress-induced immune changes in our previous study (Jiang ct al., 1990) and in other studies (Aarstad et al., 1983). Mice were placed, one at a time, in a 41 beaker filled with $1 \mathrm{l}$ of cold water $\left(10 \pm 2^{\circ} \mathrm{C}\right)$. At the end of each test, wet mice were dried to prevent hypothermia and were returned to the cage.

\section{Preparation of peritoneal macrophages}

Each mouse was injected with $1.5 \mathrm{ml}$ of thioglycolate medium (Remel, Lenexa, KS) intraperitoneally $4 \mathrm{~d}$ before death to elicit peritoneal macrophages. Animals were killed by cervical dislocation, the abdomen was cleansed with $70 \%$ ethanol, and the abdominal skin was carefully dissected without opening the peritoneum. The peritoneal cavity was then lavaged with $10 \mathrm{ml}$ of RPMI 1640 medium (Sigma, St. Louis, MO). The wash fluid was centrifuged at $400 \times g$ for $8 \mathrm{~min}$ at $4^{\circ} \mathrm{C}$. Ccll pellets [peritoneal exudate cells $(\mathrm{PEC})$ ] were resuspended in complete RPMI 1640 medium [RPMI 1640 + 10\% fetal bovine serum, 2 mM L-glutamine, $100 \mathrm{IU} / \mathrm{ml}$ penicillin, and $0.1 \mathrm{mg} / \mathrm{ml}$ streptomycin, all purchased from Sigma and determined to be low in endotoxin $(<1 \mathrm{ng} / \mathrm{ml})$ according to the manufacturer's specifications]. Ninety-six well plates (Fisher Scientific, Pittsburgh, PA) were plated with $10^{5}$ cells in $200 \mu \mathrm{l}$ per well. After a $2 \mathrm{hr}$ incubation at $37^{\circ} \mathrm{C}$ in a humidified atmosphere of $5 \% \mathrm{CO}_{2}$, adherent cells (macrophages) were obtained by washing three times with RPMI 1640 medium to remove nonadherent cells.

\section{Assay of IL-6 from peritoneal macrophages}

Supernatants were harvested and quantitated using a sandwich ELISA protocol. Ninety-six well plates were coated overnight at $4^{\circ} \mathrm{C}$ with $2 \mu \mathrm{g} / \mathrm{ml}$ purified rat anti-murine IL- 6 monoclonal antibody (mAb) (PharMingen, San Diego, CA) in $0.1 \mathrm{M} \mathrm{NaHCO}_{3}$ coating buffer, $\mathrm{pH} 8.2$, blocked with $1 \%$ bovine serum albumin (Kirkegaard \& Perry Laboratories, Gaithersburg. MD) in water for $2 \mathrm{hr}$ at room temperature, incubated with standard IL-6 (rccombinant murine IL-6, Genzyme, Cambridge, MA) or samples at room temperature for $4 \mathrm{hr}$, exposed to $2 \mu \mathrm{g} / \mathrm{ml}$ biotinylated rat anti-murine IL-6 mAb (PharMingen) at room temperature for $45 \mathrm{~min}$, incubated with $2.5 \mu \mathrm{g} / \mathrm{ml}$ avidin-peroxidase (Sigma) in PBS-Tween at room temperature for $30 \mathrm{~min}$, which was followed by adding 1:1 tetramethylbenzidine peroxidase substrate-A and peroxidase solution- $\mathrm{B}\left(\mathrm{H}_{2} \mathrm{O}_{2}\right)$ (Kirkegaard \& Perry Laboratories) at room temperature for 4-8 min. The reaction was stopped by adding $1 \mathrm{M}$ phosphoric acid. The plates were washed four times with PBS/Tween-20, pII 7.0, between steps and read at a wavelength of $450 \mathrm{~nm}$ on a Titer-Tech 96-well multiscanner, using complete RPMI 1640 medium as the blank. Samples and standards were tested in duplicate.

\section{Extraction of samples for SP-radioimmunoassay}

Peritoneal wash fluid. The peritoneal cavity was lavaged with $2 \mathrm{ml}$ of cold, low endotoxin PBS plus proteinase inhibitors $(5 \mu \mathrm{g} / \mathrm{ml}$ leupeptin, 100 $\mu \mathrm{g} / \mathrm{ml}$ chymostatin, and $300 \mu \mathrm{g} / \mathrm{ml}$ bacitracin, all purchased from Sigma) to prevent SP degradation. The wash fluid was centrifuged at $400 \times g$ for $8 \mathrm{~min}$ at $4^{\circ} \mathrm{C}$. The supernatant fluid, which will be referred to as peritoneal wash fluid throughout this article, was extracted for SP by the method of Leeman and Mroz (1974). Briefly, acetic acid was added to the peritoneal wash fluid to a final concentration of $1 \mathrm{~N}$, boiled for $5 \mathrm{~min}$, and centrifuged at $5000 \times g$ for $5 \mathrm{~min}$. The supernatant was then lyophilized overnight and kept in a $-70^{\circ} \mathrm{C}$ freezer for $\mathrm{SP}$ analysis by SPradioimmunoassay (SP-RIA).

Tissues and PEC. The boiling acetic acid method was used to extract SP in tissues and PEC (Leeman and Mroz, 1974). Briefly, $1 N$ acetic acid was added to tissues and PEC pellets. The samples were then boiled, homogenized, and centrifuged, and the supernatant was lyophilized and stored at $-70^{\circ} \mathrm{C}$ before $\mathrm{SP}$ analysis by RIA, as described above.

\section{$R I A$ of $S P$}

RIA was used to detect immunoreactive SP (iSP) in the peritoneal wash fluid, PEC, and other tissues by the method of Leeman and Mroz (1974). Briefly, the lyophilized samples were reconstituted and incubated with
$5000-6000 \mathrm{cpm} /$ tube $^{125} \mathrm{I}^{-\mathrm{Tyr}^{8}}$-SP and 1:25000 anti-SP antibody in $0.05 \mathrm{M}$ PBS, $\mathrm{pH} 7.4$, containing $0.1 \%$ gelatin (Sigma). After incubation at $4^{\circ} \mathrm{C}$ for $72 \mathrm{hr},{ }^{125}$ I-Tyr ${ }^{8}$-SP not bound to antibody was absorbed onto dextrancoated charcoal (Sigma). The amount of antibody-bound ${ }^{125} \mathrm{I}-\mathrm{Tyr}^{8}-\mathrm{SP}$ in the supernatant was determined by gamma-counter, and the values were compared with values obtained from a standard curve (incubating known amounts of unlabeled standard SP, ${ }^{125}{ }^{2} \mathrm{Tyr}^{8}-\mathrm{SP}$, and anti-SP antibody). The minimum detectable concentration of iSP is $\sim 0.5 \mathrm{fmol} /$ tube.

\section{Reversed-phase high-pressure liquid chromatography of peritoneal wash fluid}

High-pressure liquid chromatography (HPLC) was performed by the method of Kage et al. (1988). Briefly, the peritoneal wash fluid, after partial purification on Sep-pak cartridges (Waters Associates, Milford, $\mathrm{MA}$ ), was reconstituted in $0.1 \%(\mathrm{v} / \mathrm{v})$ trifluoroacetic acid, injected onto a $4.6 \times 250 \mathrm{~mm}$ Ultrasphere ODS $5 \mu \mathrm{m}$ reversed-phase HPLC column (Waters), and equilibrated with $0.1 \%(\mathrm{v} / \mathrm{v})$ trifluoroacetic acid at a flow rate of $1.5 \mathrm{ml} / \mathrm{min}$. The concentration of acelonitrile in the eluting solvent was raised to $14 \%(\mathrm{v} / \mathrm{v})$ over $5 \mathrm{~min}$, followed by an increase to $42 \%(\mathrm{v} / \mathrm{v})$ over $40 \mathrm{~min}$, and finally to $70 \%(\mathrm{v} / \mathrm{v})$ over $5 \mathrm{~min}$. Fractions $(1.5 \mathrm{ml} / 1 \mathrm{~min})$ were collected and assayed for iSP by RIA. The retention time of synthetic SP was determined

\section{Capsaicin treatment}

Mice (4-6 weeks old) were anesthetized by metofane (methoxyflurane, Pitman Moore, Mundelein, IL). Capsaicin (trans-8-methyl- $N$-vanilyl-6nonenamide, Sigma), $3 \mathrm{mg} / \mathrm{ml}$ in vehicle (10\% ethanol, $10 \%$ Tween- 80 in normal saline), was given subcutaneously three times per day for $2 \mathrm{~d}$ (Buck and Burks, 1986). The total dose of capsaicin was $50 \mathrm{mg} / \mathrm{kg}$. The control mice were given the same volume of vehicle. Tests were conducted after $\sim 1$ month.

\section{$S P$ antagonist treatment}

The SP antagonist RP67,580 and its inactive cnantiomer RP68,651 (both were generous gifts from Rhone-Poulenc Rorer) were dissolved in normal saline containing $0.05 \%$ acetic acid at a final concentration of 60 $\mu \mathrm{g} / \mathrm{ml}$. Each mouse was injected intrapcritoneally with $1.5 \mathrm{mg} / \mathrm{kg}$ before stress twice daily for $4 \mathrm{~d}$.

\section{Statistical analysis}

All data in this article are presented as mean \pm SE from individual animals. Statistical differences between treatments were evaluated either by Student's $t$ test (two-tail) (in case of two treatments; see Figs. 1, 2, 4 6,7 ) or by ANOVA (in the case of more than two treatments; see Fig. 5) taking probability $(p)$ values $<0.05$ as the threshold for significance. Fisher PLSD post hoc significance tests were used when needed.

\section{RESULTS}

\section{Cold water stress augments LPS-induced IL-6 secretion from elicited peritoneal macrophages}

Peritoneal macrophages from individual control and stressed mice were cultured with different doses of LPS for $20 \mathrm{hr}$. FI ISA determinations for IL- 6 in the culture supernatants indicated that IL-6 secretion by macrophages from stressed mice was significantly increased in response to LPS compared with macrophages from control mice at all concentrations $>12.5 \mathrm{ng} / \mathrm{ml}$. There was little or no IL-6 secretion in the absence of LPS. Macrophages, from both control and stressed mice, show a clear dose-response relationship to LPS (Fig. 1).

\section{Cold water stress increases iSP in peritoneal wash fluid}

To investigate whether exposure to cold water stress alters the content of SP in the peritoneal fluid, we examined iSP in the peritoneal wash fluid. We found a significant increase in iSP in the peritoneal wash fluids from stressed mice $(n=9)(8.72 \pm 1.94$ $\mathrm{fmol} / \mathrm{ml})$ relative to control mice $(n=9)(1.91 \pm 0.58 \mathrm{fmol} / \mathrm{ml})$ (Fig. 2). The negative control (PBS + inhibitors) showed no isP.

To further characterize iSP in the peritoneal wash fluid, fractionation by HPLC was used. In this experiment, the peritoneal 


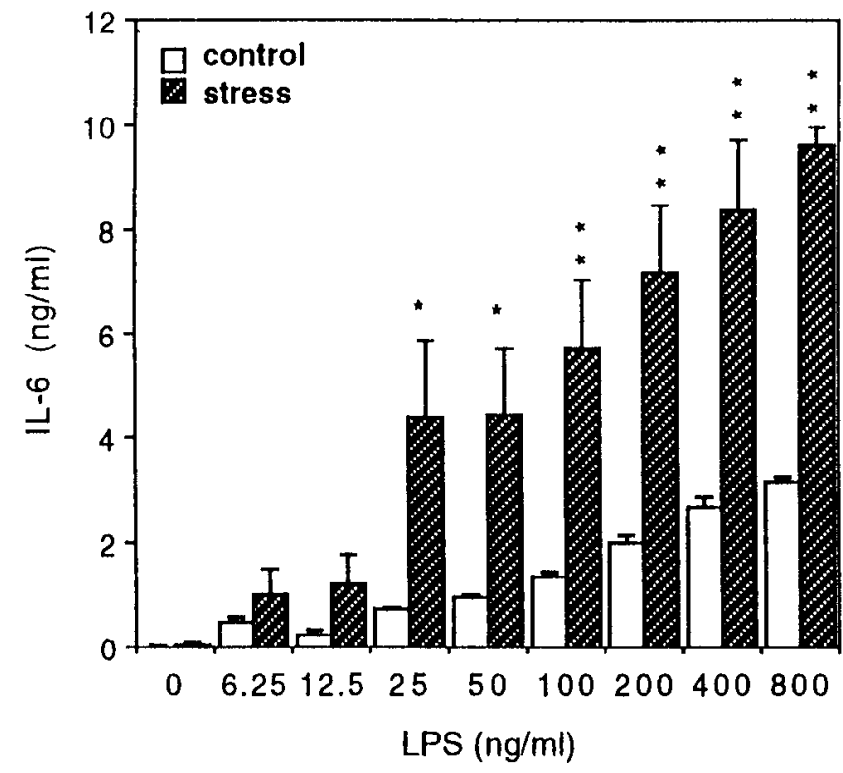

Figure 1. Cold water stress augments LPS induced IL 6 secretion from peritoneal macrophages. There were significant stress-induced increases at the LPS doses of $25 \mathrm{ng} / \mathrm{ml}\left[t_{(\mathrm{x})}=3.09 ; p<0.05\right], 50 \mathrm{ng} / \mathrm{ml}\left[t_{(y)}=2.89\right.$; $p<0.05], 100 \mathrm{ng} / \mathrm{ml}\left[t_{(9)}=3.59 ; p<0.01\right], 200 \mathrm{ng} / \mathrm{ml}\left[t_{(9)}=4.41 ; p<\right.$ $0.01], 400 \mathrm{ng} / \mathrm{ml}\left[t_{(9)}=4.74 ; p<0.01\right]$, and $800 \mathrm{ng} / \mathrm{ml}\left[t_{(5)}=15.31 ; p<\right.$ $0.01]$. The data are presented as mean \pm SE from individual animals $(n=$ 4-6) from one experiment, except for the LPS dose of $800 \mathrm{ng} / \mathrm{ml}(n=3)$, which was done in a separate experiment. ${ }^{*} p<0.05$; ${ }^{* *} p<0.01$ compared with control.

wash fluids from each group of mice (control and stress, $n=12$ each) were pooled. Reversed-phase HPLC of each pool was performed as described in Materials and Methods. SP in the peritoneal wash fluid elutes from the column with the same retention time as synthetic SP (Fig. 3). These data further suggest that iSP in the peritoneal wash fluid is authentic SP. Furthermore, the SP content in the pooled peritoneal wash fluids from stressed

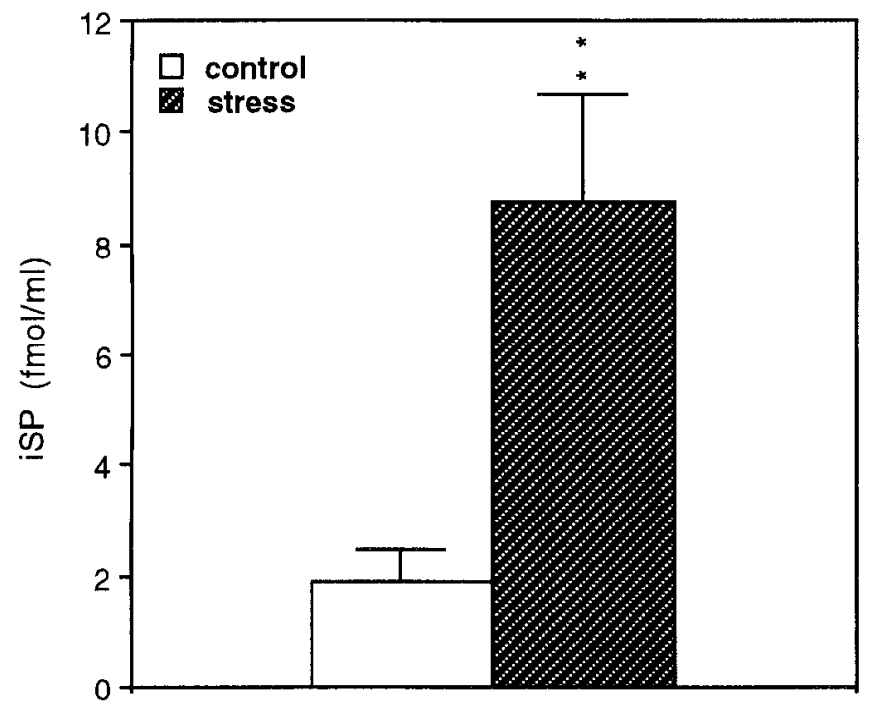

Figure 2. Cold water stress increases iSP in the peritoneal wash fluid. A significant increase in iSP is seen in the peritoneal wash fluid of the stressed mice relative to the nonstressed, control mice. The data are presented as mean \pm SE from individual animals $(n=9)$ and represent two combined experiments. ${ }^{* *} t_{(6)}=3.37 ; p<0.01$ compared with control. mice (241.98 fmol/total) was higher than the SP content in the pooled peritoneal wash fluids from control mice (116.31 $\mathrm{fmol} /$ total).

\section{SP content is altered in certain peritoneal tissues after cold water stress}

To investigate the possible sources of SP in the peritoneal fluid, we examined iSP in PEC and in selected peritoneal tissues after 4 $\mathrm{d}$ of cold water stress. We refer to peritoneal tissue as tissues and/or organs in the abdominal cavity covered by either visceral or parietal peritoneum. Levels of SP in PEC from individual as well as pooled ( $n=5$ ) ninice were undetectable.

SP content in most of the peritoneal tissues measured was slightly reduced after stress; however, a significant reduction was observed in the diaphragm, abdominal wall (peritoneum and underlying muscle), ileum, and rectum (Fig. 4). These results suggest that SP may be released from these peritoneal tissues into the peritoneal cavity after stress.

\section{There is a relationship between IL- 6 secretion from PEC and SP content in the peritoneal wash fluid and in certain peritoneal tissues during a $10 \mathrm{~d}$ cold water stress time course study}

These experiments consisted of control mice as well as mice stressed for $1,3,5,7$, and $10 \mathrm{~d}$. Data from these $10 \mathrm{~d}$ time course studies are shown in Figure 5. iSP in peritoneal tissues (in particular, the diaphragm, abdominal wall, ileum, and rectum) was reduced initially, especially after $5 \mathrm{~d}$ of stress, then gradually returned to baseline between 7 and $10 \mathrm{~d}$ of stress (Fig. 5A,R). iSP in peritoneal wash fluids became progressively elevated from 1 to $5 \mathrm{~d}$ of stress. It then returned to control levels between 7 and 10 $\mathrm{d}$ of stress (Fig. 5 C). Elevated iSP in the peritoneal wash fluid was inversely related to reduced iSP in these tissues. LPS-induced IL-6 secretion from peritoneal macrophages was increased initially at day 3 , dramatically increased by day 5 of the stress regimen, and then returned to control levels between 7 and $10 \mathrm{~d}$ of stress (Fig. $5 D$ ). Increased IL-6 shows a positive correlation with iSP in the peritoneal wash fluid.

\section{Capsaicin pretreatment eliminates stress-control differences in iSP contents in certain peritoneal tissues and in peritoneal wash fluid}

To determine whether depletion of SP could eliminate stresscontrol differences in peritoneal tissues and in peritoneal wash fluid, the neurotoxin capsaicin was used. Capsaicin is a pharmacological tool used primarily to deplete SP in nerve endings, especially unmyelinated sensory nerve endings containing SP (Buck and Burks, 1986). We therefore administered capsaicin to deplete SP in the peritoneal tissues to determine whether this affected peritoneal iSP. We found that (1) capsaicin could decrease iSP in diaphragm (59\%) and abdominal wall (83\%) and eliminate stress-control differences in iSP levels in both tissues (Fig. 6A); (2) capsaicin did not significantly deplete SP in intestines (Fig. $6 B$ ), which is consistent with previous reports (Buck and Burks, 1986; McGregor and Conlon, 1991), because the majority of SP in the intestines comes from intrinsic neurons, which are not affected by capsaicin; and (3) stress-induced SP increases in the peritoneal wash fluid were diminished by pretreatment with capsaicin (Fig. 6C). 


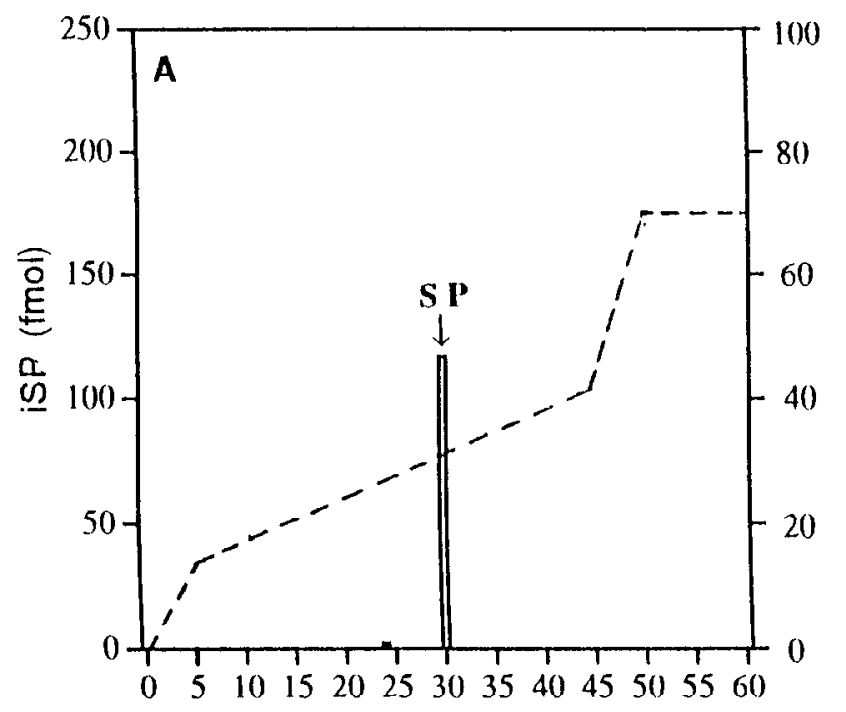

Time (min)

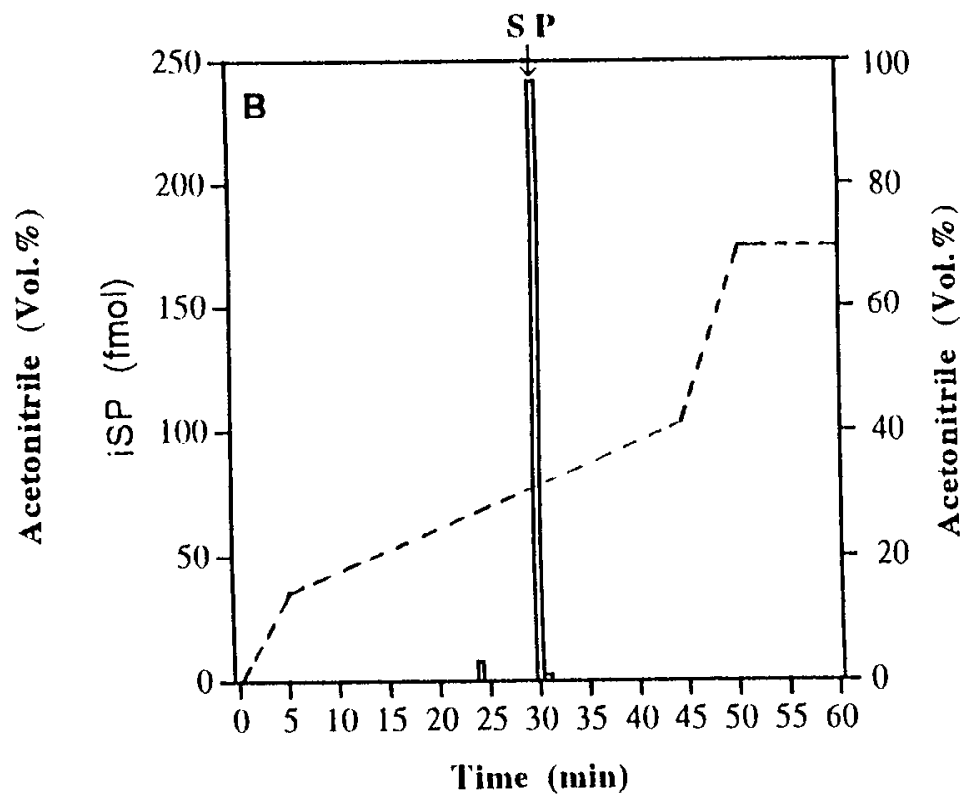

Figure 3. Reversed-phase HPLC on an Ultrasphere ODS column of peritoneal wash fluid after partial purification by Sep-pak. The bar shows the concentration of iSP in different fractions measured by RIA. The dashed line shows the concentration of acetonitrile in the eluting solvent, and the arrow shows the retention time of synthetic SP. $A$, Control; $B$, stress.

\section{The SP antagonist RP67,580 blocks the cold water stress-induced increase in IL-6 secretion from peritoneal macrophages}

To determine whether SP plays a role in the stress-induced augmentation of IL- 6 secretion from peritoneal macrophages, we used the SP antagonist RP67,580. Mice were divided into four groups: (1) control; (2) stress; (3) stress + RP68,651 (inactive enantiomer); and (4) stress + RP67,580. Animals from group 4 were injected intraperitoneally with $1.5 \mathrm{mg} / \mathrm{kg}$ of the SP antagonist RP67,580 before each stress, twice daily for $4 \mathrm{~d}$. Mice from group 3 were injected intraperitoneally with $1.5 \mathrm{mg} / \mathrm{kg}$ of the inactive enantiomer, RP68,651, before each stress, twice daily for $4 \mathrm{~d}$. All mice except controls were subjected to cold water stress twice a day for $4 \mathrm{~d}$. Peritoneal macrophages were prepared and cultured with $100 \mathrm{ng} / \mathrm{ml} \mathrm{LPS} \mathrm{for} 20 \mathrm{hr}$. Culture supernatants were harvested for IL- 6 assay by ELISA. Results indicate that the SP
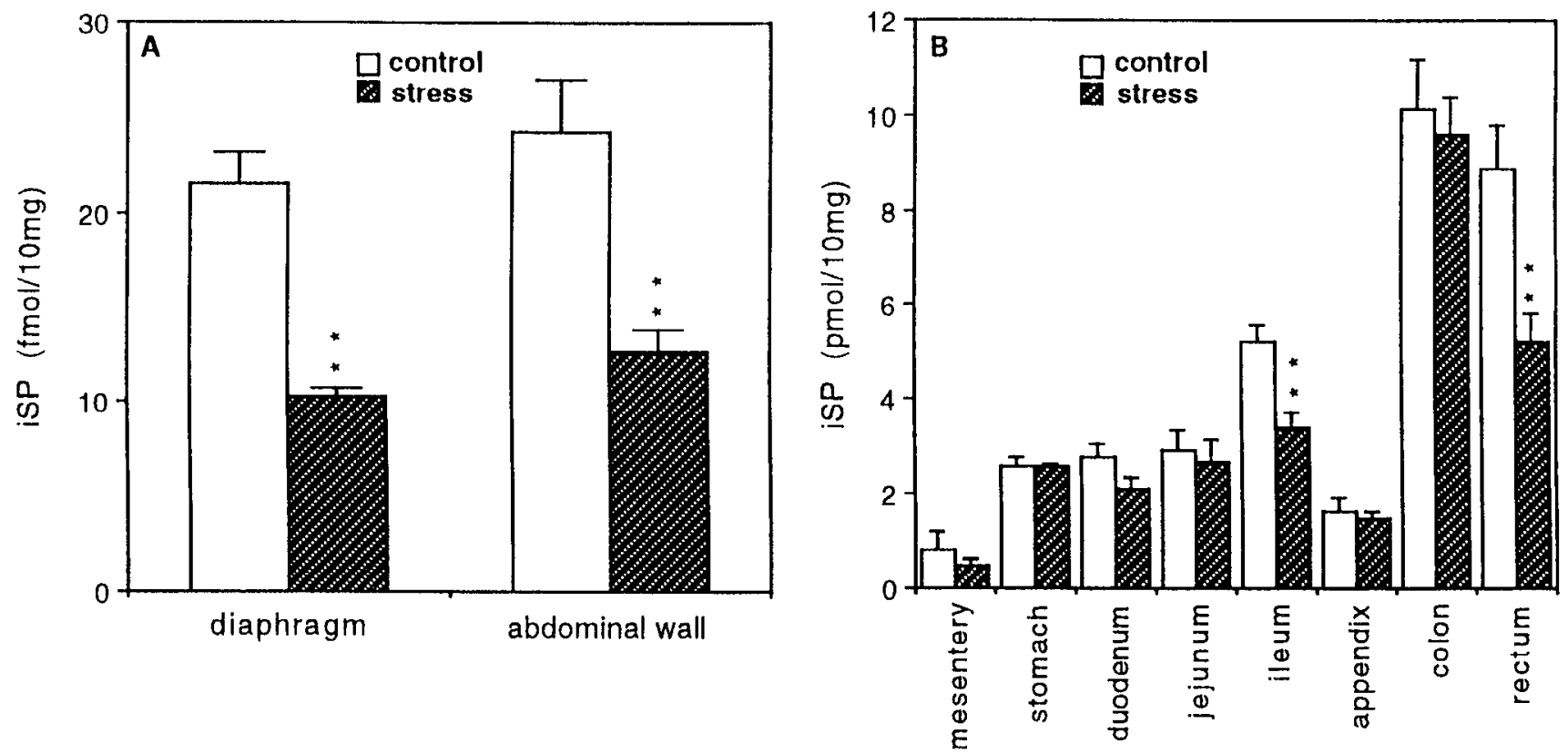

Figure 4. Stress alters iSP concentration in specific peritoneal tissues. iSP levels in diaphragm $\left[t_{(17)}=5.94 ; p<0.01\right]$ and abdominal wall $\left[t_{(18)}=3.79\right.$; $p<0.01](A)$ and ileum $\left[t_{(10)}=4.14 ; p<0.01\right]$ and rectum $\left[t_{(10)}=3.29 ; p<0.01\right](B)$ were significantly reduced after stress exposure. The data are presented as mean $\pm \mathrm{SE}$ from individual animals $(n=9-10, A ; n=6, B)$ and represent two combined experiments. ${ }^{* *} p<0.01$ compared with control. 

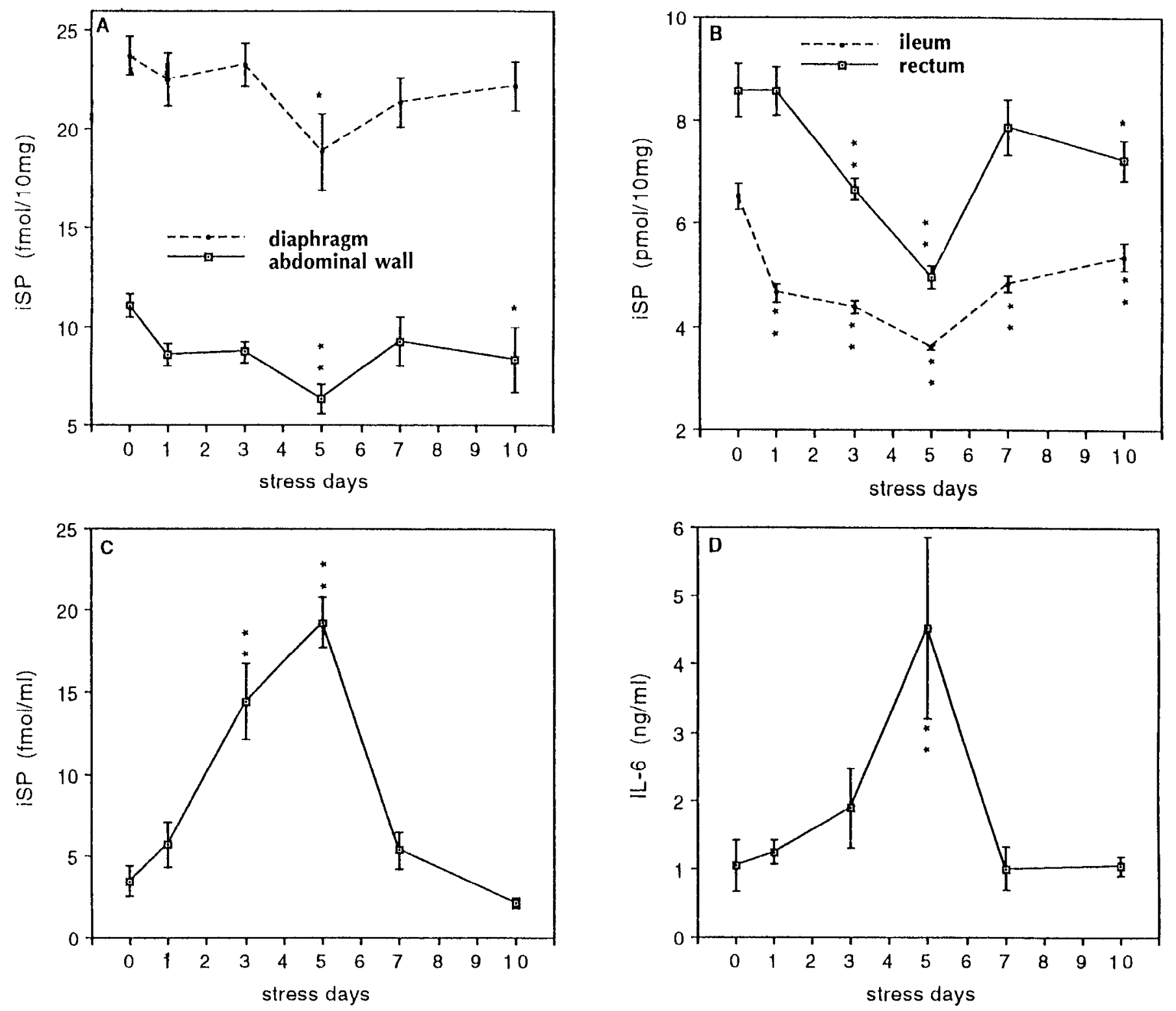

Figure 5. IL-6 secretion is related to iSP content in peritoneal wash fluids and peritoneal tissues during a $10 \mathrm{~d}$ stress regimen. iSP levels in abdominal wall $\left[F_{(5,25)}=3.14 ; p<0.05\right](A)$, and ileum $\left[F_{(5,24)}=26.16 ; p<0.01\right]$ and rectum $\left[F_{(5,24)}=10.79 ; p<0.01\right](B)$, as well as peritoneal wash fluid $\left[F_{(5,24)}\right.$ $=23.61 ; p<0.01](C)$, were significantly dependent on days of stress as determined by RIA. A main effect for days of stress was also found for LPS-induced IL-6 secretion $\left[F_{(5,22)}=4.42 ; p<0.01\right](D)$ as quantitated by ELISA. The data are presented as mean \pm SE from individual animals $(n=$ $4-5) .{ }^{*} p<0.05 ;{ }^{* *} p<0.01$ compared with control.

antagonist RP67,580, but not its inactive enantiomer RP68,651, can block cold water stress-induced enhancement of LPS-induced IL-6 secretion from peritoneal macrophages (Fig. 7).

\section{DISCUSSION}

We previously found that macrophages from stressed mice release IL-1 spontaneously and secrete more LPS-induced TNF $\alpha$ than control mice. The results reported here indicate that after cold water stress a significant enhancement of LPS-induced IL-6 secretion was found in elicited peritoneal macrophages. In other studies, various physical and psychological stressors have been reported to increase circulating levels of IL-6 (Nishimoto et al., 1989; Lemay et al., 1990; Zhou et al., 1993); however, the mediators that increase IL-6 after stress have not been delineated.

Based on the known effects of SP in modulating macrophage function, we sought to determine whether SP participates in the cold water stress-induced alteration of cytokine secretion from peritoneal macrophages. We measured SP contents in the peritoneal wash fluids of cold water stressed and nonstressed (control) mice, investigated the putative sources of peritoneal SP, and examined the stress-induced changes after depleting SP by pretreatment with capsaicin or by blocking the SP receptor by treatment with an SP antagonist.

We found that iSP in the peritoneal wash fluid was significantly increased after a $4 \mathrm{~d}$ cold water stress regimen. The determination of SP content in the peritoneal fluids is somewhat difficult because the peritoneal fluid is composed of a complex mixture of factors. Proteins and peptides are present that may cross-react with anti-SP antibody. Salts are present that may affect the binding of antigen and antibody. Each may affect the results of the RIA and give a false-positive or false-negative result. To further character- 

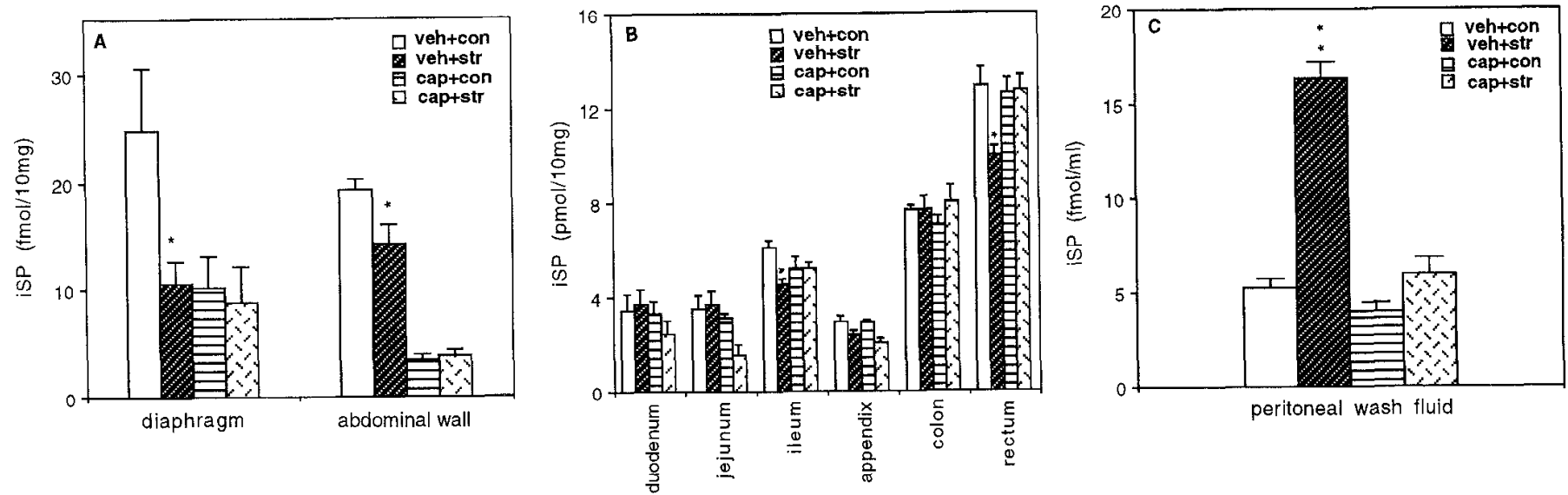

Figure 6. Capsaicin pretreatment eliminates stress-control differences in iSP concentrations in certain peritoneal tissues. There are significant stress-control differences in iSP concentrations in diaphragm $\left[t_{(8)}=2.34 ; p<0.05\right]$ and abdominal wall $\left[t_{(11)}=2.28 ; p<0.05\right](A)$, ileum $\left[t_{(11)}=4.05\right.$; $p<0.01]$ and rectum $\left[t_{(11)}=3.49 ; p<0.05\right](B)$, and peritoneal wash fluid $\left[t_{(10)}=9.64 ; p<0.01\right](C)$. The data are presented as the mean $\pm \mathrm{SE}$ from individual animals $(n=5-7)$ and represent two combined experiments. ${ }^{*} p<0.05 ;{ }^{* *} p<0.01$ compared with control.

ize iSP in the peritoneal fluid, HPLC was used. We found that both SP in the peritoneal wash fluid and synthetic SP were eluted from the column at the same time, which suggests that the iSP in the peritoneal wash fluids measured by RIA is authentic SP. Furthermore, stressed mice had higher iSP in their peritoneal wash fluids than control mice. These results further support the notion that SP is present in the peritoneal fluid and increased after cold water stress.

We next investigated the possible sources of the peritoneal SP. In the periphery, $S P$ is localized in the primary sensory neurons, in the intrinsic enteric neurons, as well as in other non-neuronal cell types, such as macrophages (Pascual and Bost, 1990; Bost et al., 1992), endothelial cells (Linnik and Moskowitz, 1989; Ralevic et al., 1990), and eosinophils (Aliakbari et al., 1987; Weinstock et al., 1988). It is possible that SP in the peritoneal cavity originated from (1) peritoneal macrophages; (2) sensory nerve endings innervating the peritoneum; or (3) sensory nerve endings and in-

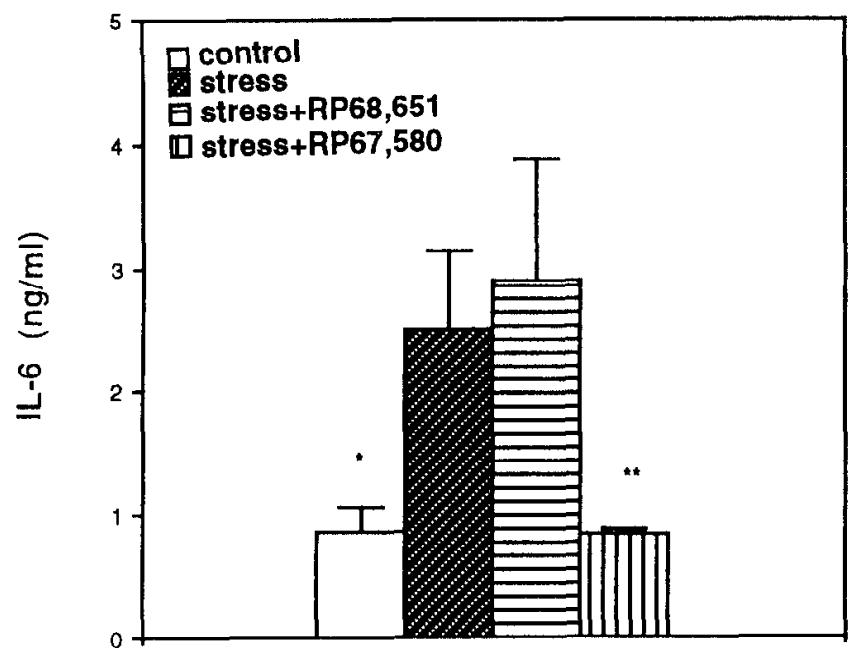

Figure 7. The SP antagonist RP67,580 blocks the cold water stressinduced increase in IL-6 secretion from peritoneal macrophages stimulated by LPS. The data are presented as mean \pm SE from individual animals ( $n=6$ for the control group and $n=8-10$ for the other groups) and represent two combined experiments. ${ }^{*} t_{(12)}=2.67 ; p<0.05 ;{ }^{* *} t_{(16)}=$ $3.33 ; p<0.01$ compared with stress. trinsic enteric neurons in the gastrointestinal tissues. Although it has been reported that P388D1 macrophages can secrete SP (Pascual and Bost, 1990; Bost et al., 1992), we were unable to detect iSP in the PEC. This result suggests that peritoneal macrophages are unlikely to be the predominant source of SP in the peritoneal cavity.

The peritoneal cavity is the space between the abdominal wall, diaphragm, and the abdominal viscera. These tissues are covered by parietal and visceral peritoneum, respectively, in which there are many sensory nerve endings containing SP. SP is synthesized in the cell bodies of neurons and transported axoplasmically for storage in the nerve endings, from which it can be released after stimulation (Häkanson et al., 1987). We hypothesized that the most likely source of SP in the peritoneal fluid came from peritoneum-containing tissues surrounding or contained within the abdominal cavity. We therefore investigated various peritoncal tissues for iSP after stress by SP-RIA. We showed that iSP is significantly reduced in the abdominal wall, diaphragm, ileum, and rectum subsequent to stress.

The $10 \mathrm{~d}$ stress time course further verifies this hypothesis and suggests a causal relationship between iSP in the peritoneal wash fluid, iSP in peritoneal tissues, and IL-6 secretion from peritoneal macrophages. In the $10 \mathrm{~d}$ stress time course study, increased IL-6 secretion appears to be directly related to elevated iSP in the peritoneal wash fluid. Furthermore, both increased IL-6 secretion and iSP in the peritoneal wash fluid appear to be inversely related to reduced iSP in certain peritoneal tissues. These data suggest that, after cold water stress, SP is released from peritoneal tissues into the peritoneal cavity, where SP could modulate macrophage function.

To further define the role of SP in the demonstrated stressinduced changes, we studied the stress response in mice that had been pretreated with capsaicin. In our experiment, pretreatment with capsaicin significantly reduced iSP in the diaphragm and abdominal wall. After capsaicin induced depletion of SP in the peritoneal tissues, SP would be unable to be released into the peritoneal fluid, thus providing a mechanism for the reduction in the stress-induced increase in iSP in the peritoneal wash fluid.

To determine whether SP plays a role in the stress-induced augmentation of $1 \mathrm{~L}-6$ secretion, we attempted to block the SP receptors by an SP antagonist. We used the nonpeptide SP an- 
tagonist RP67,580 based on its known potent and specific effects in rats and mice (Garret et al., 1991). Our results indicate that intraperitoneal injection of RP67,580 can block the stress-induced increase in IL-6 from peritoneal macrophages, whereas intraperitoneal injection of its inactive enantiomer RP68,651 cannot. These results strongly suggest that SP contributes to the augmentation of LPS-induced IL-6 secretion induced by stress and confirm the in vivo capsaicin data.

SP is a known mediator of neuroinflammation (Otsuka, 1993). There is also evidence that SP released from the terminals of capsaicin-sensitive afferent neurons plays an important role in non-neural inflammatory processes (McGillis et al., 1988; Payan, 1989; Mantyh et al., 1991). High-affinity receptors have been found on a number of immune cells known to participate in inflammatory reactions, including lymphocytes (Payan et al., 1984), mast cells (Piotrowski et al., 1987), and macrophages (Hartung et al., 1986). Indeed, macrophages arriving at the site of neural injury or inflammation, or other inflammatory reactions, presumably by SP chemotaxis, have been shown to have increased SP binding, suggesting that SP may induce SP receptor synthesis/ expression (McGillis et al., 1988; Mantyh et al., 1989).

The studies presented herein indicate that stress can modulate macrophage function to produce cytokines by an SP-dependent mechanism. Increased cytokines induce acute phase reactants (APR) in the liver, which is presumably the mechanism operative in the studies indicating increases in APR after certain stressors in animals (Morimoto et al., 1989). Thus, the two essential preliminary events required for an inflammatory reaction-proinflammatory cytokine and APR production - may be caused by stress. Stress, therefore, may be operative in the pathogenesis of certain inflammatory diseases such as rheumatoid arthritis, for example, for which there is no known etiology. In this regard, it is of interest that elevated SP is found in human joints inflamed by rheumatoid arthritis (Devillier et al., 1986; Marshall et al., 1990). Moreover, adjuvant-induced arthritis is more likely to be induced in more densely relative to more sparsely innervated joints (Levine et al., 1984) and cannot be induced in a denervated limb (Lotz et al., 1987; Garrett et al., 1992).

In summary, our evidence suggests that cold water stress can promote the release of SP from sensory nerve endings innervating the peritoneal tissues, into the peritoneal cavity. Here it likely interacts with SP receptors on the macrophage, to mediate the stress-induced macrophage functional alterations. We therefore postulate that SP is an important link between the nervous and immune systems and participates in the response to stress by modulating macrophage function to produce inflammatory mediators, which are essential in the initiation of the inflammatory response.

\section{REFERENCES}

Aarstad H.I, Gardennack G, Selfedid R (1983) Stress causes reduced natural killer activity in mice. Scand J Immunol 18:461-464.

Adams DO (1994) Molecular biology of macrophage activation: a pathway whereby psychosocial factors can potentially affect health. Psychosom Med 56:316-327.

Aliakbari J, Sreedharan SP, Turck CW, Goetzl EJ (1987) Selective localization of vasoactive intestinal peptide and substance $P$ in human eosinophils. Biochem Biophys Res Commun 148:1440-1445.

Black PH (1994a) Central nervous system-immune system interactions: psychoneuroendocrinology of stress and its immune consequences. Antimicrob Agents Chemother 38:1-6.

Black PH (1994b) Immune system-central nervous system interactions: effect and immunomodulatory consequences of immune system mediators on the brain. Antimicrob Agents Chemother 38:7-12.
Black PH (1995) Psychoneuroimmunology: brain and immunity. Sci Med 2:16-25.

Bost KL (1988) Hormone and neuropeptide receptors on mononuclear leukocytes. Prog Allergy 43:68-83.

Bost KL, Breeding SA, Pascual DW (1992) Modulation of the mRNAs encoding substance $P$ and its receptor in rat macrophages by LPS. Reg Immunol 4:105-112.

Brown DH, Zwilling BS (1994) Activation of the hypothalamic-pituitary-adrenal axis differentially affects the anti-mycobacterial activity of macrophages from BCG-resistant and susceptible mice. J Neuroimmunol 53:181-187.

Buck SH, Burks TF (1986) The neuropharmacology of capsaicin: review of some recent observations. Pharmacol Rev 38:179-226.

Coe CL, Rosenberg LT, Levine S (1988) Prolonged effect of psychological disturbance on macrophage chemiluminescence in the squirrel monkey. Brain Behav Immun 2:151-160.

Devillier P, Neill B, Renoux M, Menkes C, Pradilles P (1986) Elevated levels of tachykinin-like immunoreactivity in joint fluids for patients with rheumatoid arthritis. N Engl J Med 314:1323.

Fleshner M, Rellgrau D, Watkins LR, Laudenslager ML, Maier SF (1995) Stress-induced reduction in the rat mixed lymphocyte reaction is duc to macrophages and not to changes in $\mathbf{T}$ cell phenotypes. $\mathbf{J}$ Neuroimmunol $56: 45-52$.

Garret C, Carruette A, Fardin V, Moussaoui S, Peyronel JF, Blanchard JC, Laduron PM (1991) Pharmacological properties of a potent and selective nonpeptide substance $P$ antagonist. Proc Natl Acad Sci USA 88:10208-10212.

Garrett NE, Mapp PI, Cueyys SC, Kidd BL, Blake DR (1992) Role of substance $P$ in inflammatory arthritis. Ann Rheum Dis 51:1014-1018.

Häkanson R, Beding B, Ekman R, Heiligm M, Wahlestedı C, Sundler F (1987) Multiple tachykinin pools in sensory nerve fibers in the rabbit iris. Neuroscience 21:943-950.

Hartung HP (1988) Activation of macrophages by neuropeptides. Brain Behav Immun 2:275-281.

Hartung HP, Wolters K, Toyka KV (1986) Substance P: binding properties and studics on cellular responses in guinea pig macrophages. J Immunol 136:3856-3863.

Irwin M (1993) Stress-induced immune suppression. Role of the autonomic nervous system. Ann NY Acad Sci 697:203-218.

Jiang CG, Morrow-Tesch JL, Beller DI, Levy EM, Black PH (1990) Immunosuppression in mice induced by cold water stress. Brain Behav Immun 4:278-291.

Kage R, McGregor GP, Thim L, Coular JM (1988) Ncuropeptidegamma: a peptide from rabbit intestine that is derived from gammapreprotachykinin. J Neurochem 50:1412-1417.

Kimball ES, Persico FJ, Vaught JL (1988) Substance P, neurokinin A, and neurokinin $B$ induce generation of IL-1-like activity in P388D I cells. Possible relevance to arthritic disease. J Immunol 141:3564-3569.

Kroegel C, Giembycz MA, Barnes PJ (1990) Characterization of cosinophil cell activation by peptides: differential effects of substance $P$, melittin, and FMET-Leu-Phe. J Immunol 145:2581-2587.

Laurenzi MA, Persson MA, Dalsgaard CJ, Haegerstrand A (1990) The neuropeptide substance $P$ stimulates production of interleukin 1 in human blood monocytes: activated cells are preferentially influenced by the neuropeptide. Scand J Immunol 31:529-533

Leeman SE, Mroz EA (1974) Substance P. Life Sci 15:2033-2044.

LeMay LG, Vander AJ, Kluger MJ (1990) The effects of psychological stress on plasma interlcukin-6 activity in rats. Physiol Behav 47:957-961.

Levine JS, Clark R, Devar M, Helms C, Maskowitz A, Basuaum AI (1984) Intrancural substance $P$ contributes to the severity of experimental arthritis. Science 226:547-549.

Linnik MD, Moskowitz MA (1989) Identification of immunoreactive substance $P$ in human and other mammalian endothelial cells. Peptides $10: 957-962$.

Lloyds D, Hallett MB (1993) Activation and priming of the human neutrophil oxidase response by substance $P$ : distinct signal transduction pathways. Biochem Biophys Acta 1175:207-213.

Lloyds D, Brindle NP, Hallett MB (1995) Priming of human ncutrophils by tumour necrosis factor-alpha and substance $\mathrm{P}$ is associated with tyrosine phosphorylation. Immunology 84:220-226.

Lotz M, Carson DA, Vaughan JH (1987) Substance P activation of rheumatoid synoviocytes: neural pathways in pathogenesis of arthritis. Science 235:893-895. 
Lotz M, Vaughan JH, Carson DA (1988) Effect of neuropeptides on production of inflammatory cytokines by human monocytes. Science 241:1218-1221.

Lubcr-Narod J, Kage R, Lecman SE (1994) Substance P cnhances the secretion of tumor necrosis factor-alpha from neuroglial cells stimulated with lipopolysaccharide. J Immunol 152:819-824.

Mantyh PW, Johnson DJ, Boehmer CG, Catton MD, Vinfers HV, Maggio JE, Too HP, Vigna SR (1989) Substance P receptor binding sites are expressed by glia in vivo after neuronal injury. Proc Natl Acad Sci USA 86:5193-5197.

Marshall KW, Chiu B, Inman RD (1990) Substance P and arthritis: analysis of plasma and synovial fluid levels. Arthritis Rheum 33:87-90.

Martin FC, Anton PA, Gornbein JA, Shanahan F, Merrill JE (1993) Production of interleukin-1 by microglia in response to substance P: role for a non-classical NK-1 receptor. J Neuroimmunol 42:53-60.

McGillis JP, Mitsuhashi M, Payan DG (1990) Immunomodulation by tachykinin neuropeptides. Ann NY Acad Sci 594:85-94.

McGregor GP, Conlon JM (1991) Regulatory peptide and serotonin content and bruch-border enzyme activity in the rat gastrointestinal tract following neonatal treatment with capsaicin; lack of effect on epithelial markers. Regul Pept 32:109-119.

Morimoto A, Watanabe T, Myogin T, Morakami N (1987) Restraint stress elicits acute-phase response in rabbits. Eur J Physiol 410:554-556.

Nishimoto N, Yoshizaki K, Tagoh H, Mondedn M, Kishimoto S, Hirano T, Kishimoto T (1989) Elevation of serum interleukin 6 prior to acute phase proteins on the inflammation by surgical operation. Clin Immunol Immunopathol 50:399-401.

Otsuka M, Yoshioka K (1993) Neurotransmitter functions of mammalian tachykinins. Physiol Rev 73:229-308.

Ottaway CA, Husband AJ (1994) The influence of neuroendocrine pathways on lymphocyte migration. Immunol Today 15:511-517.

Pascual DW, Bost KL (1990) Substance P production by P388D1 macrophages: a possible autocrine function for this neuropeptide. Immunology 71:52-56.

Payan DG (1989) Neuropeptides and inflammation: the role of substance P. Annu Rev Med 40:341-352.
Payan DG, Brewster DR, Goetzl EJ (1984) Stereospecific receptors for substance $P$ on cultured human IM-9 lymphoblasts. J Immunol 133:3260-3265

Pcrianin A, Snyderman R, Malfroy B (1989) Substance P primes humal neutrophil activation: a mechanism for neurological regulation of inflammation. Biochem Biophys Res Commun 161:520-524.

Pernow B (1983) Substance P. Pharmacol Rev 35:85-141.

Piotrowski W, Mead M, Foreman JC (1987) Action of the SP2-11 and SP3-11 fragments of substance $P$ on rat peritoneal mast cells. Agents Actions 20:178-180.

Ralevic V, Milner P, Hudlicka O, Kristek F, Burnstock G (1990) Substance $\mathrm{P}$ is released from the endothelium of normal and capsaicintreated rat hind-limb vasculature, in vivo, by increased flow. Circ Res 65:1178-1183.

Rameshwar P, Gascon P (1995) Substance P (SP) mediates production of stem cell factor and interleukin-1 in bone marrow stroma: potential autoregulatory role for these cytokines in SP receptor expression and induction. Blood 86:482-490.

Rameshwar P, Ganea D, Gascon P (1993) In vitro stimulatory effect of substance $\mathbf{P}$ on hematopoiesis. Blood 81:391-398.

Rameshwar P, Ganea D, Gascon $P$ (1994) Induction of IL-3 and granulocyte-macrophage colony-stimulating factor by substance $P$ in bone marrow cells is partially mediated through the release of IL-1 and IL-6. J Immunol 152:4044-4054.

Stanisz AM, Scicchitano R, Dazin P, Bienenstock J, Payan DG (1987) Distribution of substance $P$ receptors on murine spleen and Peyer's patch $\mathrm{T}$ and $\mathrm{B}$ cells. J Immunol 139:749-754.

Ursin H (1994) Stress, distress, and immunity. Ann NY Acad Sci $741: 204-211$.

Weinstock JV, Blum A, Walder J, Walder R (1988) Eosinophils from granulomas in murine schistosomiasis mansoni produce substance $\mathbf{P}$. $\mathbf{J}$ IIIIIIUnol 141:961-966.

Zhou D, Kusnecov AW, Shurin MR, DePaoli M, Rabin BS (1993) Exposure to physical and psychological stressors elevates plasma interleukin 6: relationship to the activation of hypothalamic-pituiatry-adrenal axis. Endocrinology 133:2523-2530. 